\title{
Compressive Strength Performance of Alkali Activated Concretes under Different Curing Conditions
}

\author{
Anıl Niş ${ }^{1 *}$, ilhan Altındal ${ }^{1}$ \\ ${ }^{1}$ Department of Civil Engineering, Istanbul Gelisim University, 34315, Istanbul, Turkey \\ * Corresponding author, e-mail: anis@gelisim.edu.tr
}

Received: 10 August 2020, Accepted: 19 January 2021, Published online: 28 January 2021

\begin{abstract}
This study investigated the influence of different curing conditions on the compressive strength (CS) of the different alkali activated concrete (AAC) specimens at the ages of 2, 28, and 90 days for the structural utilization and standardization process of AAC instead of OPC concrete. For this aim, $100 \%$ slag (S100), $75 \%$ slag and $25 \%$ fly ash (S75FA25), and $50 \%$ slag and $50 \%$ fly ash based (S50FA50) AAC specimens were produced. Based on the oven-curing $(\mathrm{O})$, water-curing $(\mathrm{W})$, and ambient-curing $(A)$ methods, the influence of 20 for 2 days, 26A2O, 2026A, 28A, 28W, 26W2O, and 2026W for 28 days, and 88A2O, 2088A, 90A, 88W20, 2088W, $90 \mathrm{~W}$ for 90 days on the CS of the AAC were examined in details. In addition, the influence of delayed oven-curing conditions on CS development was also investigated. The results indicated that curing conditions significantly affected on the CS and the water-curing condition could provide a better CS for those of AAC at 90 days. Although, the oven-curing enhanced CS of the S100 specimens at initial ages (first oven-curing applied), delayed oven-curing (oven-curing applied later) was found significant for S75FA25 and S50FA50 specimens. The delayed oven-curing affected more on the CS of the AAC when fly ash content increased. The most of AAC specimens with oven-curing had significantly enhanced the CS at 28 days, but S50FA50 at the age of 90 days decreased. Different curing regimes were proposed for the superior compressive strength values for each AAC specimens at the ages of 28 and 90 days.
\end{abstract}

Keywords

oven-curing, delayed oven-curing, water-curing, curing conditions, alkali activated concrete

\section{Introduction}

Ordinary Portland cement (OPC) concrete is one of the most used materials in the construction of structural buildings. Due to its easy and local accessibility, and low prices as compared to steel, OPC concrete utilization is considered to be increased further in the upcoming years. However, huge quantity of energy is needed and high amount of $\mathrm{CO}_{2}$ is emitted during OPC production, causing a detrimental effect to both economy and environment. Therefore, sustainable alternative construction materials to produce concrete are required for a greener environment. Due to its inorganic binding property and environmental friendliness nature, alkali activated concrete (AAC) emerges as an alternative environmental construction material compared to OPC concrete. A novel cement-free material, alkali activated concrete (AAC) releases approximately 6 times lower $\mathrm{CO}_{2}$ amount than $\mathrm{OPC}$ concrete [1] and $\mathrm{AAC}$ requires low amount of energy in the production phase [2]. The utilization of AAC in the construction industry may result in improved sustainability, low energy consumption, reduced greenhouse gases, which can be a solution for the reduced climatic change and the low carbon footprint.

Alkali activated concrete (AAC) is produced by the reaction between alumina and silica based materials and alkali activators. The ground granulated blast furnace slag (GGBFS), fly ash (FA), and calcined clays are commonly utilized precursors, and the potassium and sodium silicates and hydroxides are the most utilized alkali activators [3]. The other raw materials, ceramic tile powder [4], natural volcanic pozzolan [5], coconut shell ash [6], red mud [7] can be utilized in the production of AAC specimens. AAC has superior mechanical properties depending on the source of the alumina and silica based precursors and alkali activators, such as high compressive strength [8], superior sulphate, seawater and sulfuric acid resistance [9, 10], low drying shrinkage [11], and fire resistance [12]. 
The GGBFS is generally utilized as a calcium-rich aluminosilicate precursor in AAC materials. Due to the high calcium, GGBFS material can be utilized alone in the AAC materials or it is mixed with F-type fly ash to enhance the reactivity of low-calcium fly ash particles when cured in ambient temperature [10]. The higher amount of slag utilization enhanced the compressive strength of the AAC materials, however, $70 \%$ or more slag utilization results in rapid setting and autogenous shrinkage cracks [13]. Meanwhile, low calcium fly ash based geopolymer specimens needs to be cured under elevated temperatures above $60^{\circ} \mathrm{C}$ to have superior mechanical performance [14]. Therefore, in most cases, both blast furnace slag and low calcium fly ash is used to eliminate heat-curing, decrease rapid setting and shrinkage cracks and to enhance the workability of AAC. In addition to aluminosilicate precursor, alkali activator types and their utilization ratios (such as SS/SH) [15], elevated curing temperature and duration [16] also plays significant role for the mechanical strength of the AAC specimens. For the alkali activators, together use of sodium silicate and sodium hydroxide solutions are most utilized alkali activator types for AAC since it was found in the previous study that sodium based alkali activators was found to be more efficient than the potassium based alkali activators for the fly ash activation [17].

The curing method is a significant parameter to obtain superior compressive strength (CS) and durability performance for the structural utilization of AAC, especially for the fly ash including AAC. It was reported that alkali activation of fly ash increased with an increase in the curing temperature [18]. For the complete dissolution of fly ash particles in the AAC, the oven-curing should be higher than $40^{\circ} \mathrm{C}$ [19]. In another investigation [20], CS enhancement was found to be approximately $100 \%$ when the curing temperature increased to $80^{\circ} \mathrm{C}$. In general, elevated temperature accelerates the early strengths of the alkali activated materials [21]. In addition, the curing duration also influences the CS results. In a study [22], the CS enhancement was stabilized at the age of 56 days for slag based AAC specimens without heat-curing, whereas CS of the fly ash based geopolymer concretes improved at the ages of 540 days even though the initial curing application at $80^{\circ} \mathrm{C}$ for $24 \mathrm{~h}$. In another research, the effects of three different oven-curing temperatures $\left(30^{\circ} \mathrm{C}, 60^{\circ} \mathrm{C}\right.$, and $\left.90^{\circ} \mathrm{C}\right)$ and 3 various curing durations ( 1 day, 2 days, and 3 days) were examined on the slag based AAC specimens. The obtained results pointed out that curing temperature increase adversely influenced the CS values of AAC. In addition, the optimum curing duration was found as 2 days for the slag based specimens [23] and the CS enhancement due to the oven-curing was found insignificant after $48 \mathrm{~h}$ [24]. It was also reported that oven-curing application caused a decrease in the drying shrinkage and improved preliminary CS. However, a CS decrease was found at later ages due to the inhomogeneous distributions of geopolymeric reaction products in the matrix [25].

In addition to oven-curing, the moist curing also affected the CS enhancement of the AAC. In the previous study [26], the influence of moist curing on AAC examined and it was found that moist cured specimens yielded higher CS and low porous system with respect to ambient curing condition. This was attributed to the water evaporation due to the ambient curing, which decreases the available water for the geopolymerization products. Another reason of the CS reduction for the ambient cured specimens may be attributed to the efflorescence and micro cracking due to the dehydration [27].

Although, there are numerous investigation regarding the oven-curing temperatures and durations for the AAC specimens, there are no or very few study exist regarding the evaluation of water-curing, ambient-temperature and oven curing conditions on the CS of different AAC at different ages. Since ongoing special concrete applications, such as shotcrete, post-tension, roller-compacted, self-compacting, lightweight or heavy weight concrete applications, it is significant to obtain required knowledge regarding the different curing conditions on the compressive strength development for the structural utilization and standardization process of the AAC. For this aim, the influence of 13 different curing conditions on the CS of the $100 \%$ ground granulated blast furnace slag, $75 \%$ slag and $25 \%$ F-type fly ash, and $50 \%$ slag and $50 \%$ fly ash based alkali activated concrete specimens were examined in details. In addition, the influence of delayed oven-curing condition was also investigated since this type of oven-curing can be significant for the structural utilization, especially for the mass concrete and post-tension concrete applications.

\section{Experimental program \\ 2.1 Materials and mix design}

In the scope of the research, ground granulated blast furnace slag (S) and F type fly ash (FA) and were used to achieve $100 \%$ ground granulated blast furnace slag based alkali activated concrete (S100), $75 \%$ ground granulated blast furnace slag and $25 \%$ F-type fly ash based alkali activated concrete (S75FA25), $50 \%$ ground granulated blast 
furnace slag and $50 \%$ F-type fly ash based alkali activated concrete (S50FA50) specimens. For the alkali activation of the alkali activated concretes, a mixture of sodium silicate $\left(\mathrm{Na}_{2} \mathrm{SiO}_{3}\right)$ and sodium hydroxide $(\mathrm{NaOH})$ with a $2.5 / 1$ ratio by weight was utilized. The sodium hydroxide solution was prepared in the laboratory by dissolving sodium hydroxide powders in water to achieve $14 \mathrm{M}$ sodium hydroxide. The $14 \mathrm{M}$ concentration was selected since it was considered as the weakest concentration amount under chemical environments [28]. The sodium silicate solution was taken from a local chemical market with an alkaline modulus of 2. A mixture of sodium silicate by weight of 2.5 , and $14 \mathrm{M}$ sodium hydroxide by weight of 1 was prepared in a laboratory and the obtained mixture was left to cool about 30 min before utilization. As a superplasticizer, a naphthalene sulfonate based superplasticizer was utilized to achieve S4 slump class concrete. Coarse aggregates; No I and No II with specific gravities of $2.71 \mathrm{~g} / \mathrm{cm}^{3}$ and $2.72 \mathrm{~g} / \mathrm{cm}^{3}$ were used with a maximum grain size of $22 \mathrm{~mm}$, and natural sand and crushed sand with specific gravities of $2.60 \mathrm{~g} / \mathrm{cm}^{3}$ and $2.70 \mathrm{~g} / \mathrm{cm}^{3}$ were used as fine aggregates. Table 1 indicates the properties of the slag and fly ash materials.

During the AAC casting period, dry materials (precursor solids and aggregates) were added and mixed $2 \mathrm{~min}$, then the mixed alkali activators and half of SP were included and mixed at $2 \mathrm{~min}$, finally the additional water and the remained SP were included and mixed at $2 \mathrm{~min}$ in the mixer. For the workability improvement and further alkali activation, additional water utilization into the mixes was also reported in the previous investigations [1].

For the production of the AACs, alkali activation solution/binder ratio was selected as 0.45 . However, in order to obtain S4 slump class concrete and to produce economic AAC, additional water is added into the AACs. For the workability, the additional water to alkali activator solid ratio was selected as 0.34 , and the sum of the additional water and alkali activation solution/binder ratio was used as 0.58 . The utilized binder content was kept constant as $360 \mathrm{~kg} / \mathrm{m}^{3}$ for the AACs. Table 2 shows the mix proportions of the AACs.

The obtained mixtures were poured into the $150 \times 150 \times$ $150 \mathrm{~mm}$ cube specimens for CS tests. For each mixes, three specimens were cast to obtain average values. During casting period, required compaction was applied and the top section was covered with plastic sheets to hinder alkali activator evaporations. The poured specimens were left to laboratory environment for 2 days and then specimens were demolded due to the slow geopolymeric reactions

\begin{tabular}{lcc}
\multicolumn{3}{l}{ Table 1 Chemical composition and physical properties of the materials } \\
\hline Chemical Composition & Slag & Fly Ash \\
\hline $\mathrm{CaO}(\%)$ & 37.92 & 1.79 \\
$\mathrm{Al}_{2} \mathrm{O}_{3}(\%)$ & 13.27 & 26.37 \\
$\mathrm{SiO}_{2}(\%)$ & 37.97 & 56.15 \\
$\mathrm{Fe}_{2} \mathrm{O}_{3}(\%)$ & 1.16 & 6.44 \\
$\mathrm{MgO}(\%)$ & 5.64 & 2.35 \\
$\mathrm{SO}_{3}(\%)$ & 0.23 & 0.056 \\
$\mathrm{Na}_{2} \mathrm{O}(\%)$ & 0.84 & 1.1 \\
$\mathrm{~K}_{2} \mathrm{O}(\%)$ & 0.56 & 3.8 \\
$\mathrm{Cl}(\%)$ & 0.015 & 0.09 \\
Loss on ignition $(\%)$ & 0.01 & 2.2 \\
Specific Gravity $\left(\mathrm{g} / \mathrm{cm}^{3}\right)$ & 2.95 & 2.05 \\
Specific Surface $\left(\mathrm{cm}^{2} / \mathrm{g}\right)$ & 5131 & 3870 \\
\hline
\end{tabular}

Table 2 Mix proportions of S100, S75FA25, and S50FA50 specimens

\begin{tabular}{lccc}
\hline Ingredients (kg) & S100 & S75FA25 & S50FA50 \\
\hline Slag & 360 & 270 & 180 \\
Fly Ash & 0 & 90 & 180 \\
No I (5-12mm) & 560 & 560 & 560 \\
No II (12-22mm) & 560 & 560 & 560 \\
Crushed sand & 373 & 373 & 373 \\
Sand & 373 & 373 & 373 \\
Sodium silicate & 115.7 & 115.7 & 115.7 \\
Sodium hydroxide & 46.3 & 46.3 & 46.3 \\
Superplasticizer & 31.25 & 31.25 & 31.25 \\
Water & 46.3 & 46.3 & 46.3 \\
\hline
\end{tabular}

of the fly ash including mixes. After, 13 different curing methods were applied to the various AAC specimens to obtain required knowledge about the influence of the curing conditions on the CS development.

\subsection{Curing conditions}

The study aims to investigate the influence of different curing conditions on the CS behavior of the slag/fly ash based AACs. Table 3 summarizes the curing conditions at the ages of 2, 28, and 90 days for the AACs. The aim of the testing $2 \mathrm{O}$ condition was to learn the influence of the oven-curing on the CS development at early ages, especially for the fly ash including AACs. The oven-cured specimens at $70^{\circ} \mathrm{C}$ for $48 \mathrm{~h}$ were indicated as $2 \mathrm{O}$. The oven-curing was applied to the AACs at $70^{\circ} \mathrm{C}$ for $48 \mathrm{~h}$ since the CS enhancement became insignificant $48 \mathrm{~h}$ later [24]. The influence of delayed oven-curing (DOC) condition was also investigated since this type of curing can be significant for the special concrete application, such as mass concrete and post-tension applications. Therefore, some 
Table 3 Curing methods of the S100, S75FA25, and S50FA50 specimens

\begin{tabular}{lr}
\hline Notation & Curing Methods \\
\hline $2 \mathrm{O}$ & 2 days oven-curing at $70^{\circ} \mathrm{C}$ for $48 \mathrm{~h}$ \\
$26 \mathrm{~A} 2 \mathrm{O}$ & 26 days under lab +2 days oven-curing at $70^{\circ} \mathrm{C}$ for $48 \mathrm{~h}$ \\
$2 \mathrm{O} 26 \mathrm{~A}$ & 2 days oven-curing at $70^{\circ} \mathrm{C}$ for $48 \mathrm{~h}+26$ days under lab \\
$28 \mathrm{~A}$ & 28 days under lab at ambient temperature \\
$28 \mathrm{~W}$ & 28 days under water \\
$26 \mathrm{~W} 2 \mathrm{O}$ & 26 days under lab +2 days in an oven at $70^{\circ} \mathrm{C}$ for $48 \mathrm{~h}$ \\
$2 \mathrm{O} 26 \mathrm{~W}$ & 2 days oven-curing at $70^{\circ} \mathrm{C}$ for $48 \mathrm{~h}+26$ days under water \\
$88 \mathrm{~A} 2 \mathrm{O}$ & 88 days under lab +2 days in an oven at $70^{\circ} \mathrm{C}$ for $48 \mathrm{~h}$ \\
$2 \mathrm{O} 88 \mathrm{~A}$ & 2 days in an oven at $70^{\circ} \mathrm{C}$ for $48 \mathrm{~h}+26$ days under lab \\
$90 \mathrm{~A}$ & 90 days under laboratory at ambient temperature \\
$88 \mathrm{~W} 2 \mathrm{O}$ & 88 days under water +2 days oven-curing at $70^{\circ} \mathrm{C}$ for $48 \mathrm{~h}$ \\
$2 \mathrm{O} 88 \mathrm{~W}$ & 2 days in an oven at $70^{\circ} \mathrm{C}$ for $48 \mathrm{~h}+26$ days under lab \\
$90 \mathrm{~W}$ & 90 days under water
\end{tabular}

of the specimens cured at ambient temperature up to $26 \mathrm{~d}$, later oven curing applied at $70^{\circ} \mathrm{C}$ for $48 \mathrm{~h}$ were notated as $26 \mathrm{~A} 2 \mathrm{O}$ to investigate the effect of DOC condition on the $\mathrm{CS}$ development. In addition, some of the specimens cured in an oven at $70^{\circ} \mathrm{C}$ for $48 \mathrm{~h}$ and then cured at ambient temperature were shown as 2026A, and some of them cured at ambient temperature for 28 days were named as $28 \mathrm{~A}$ to learn the influence of the oven-curing conditions on the CS of the specimens at 28 days.

The influence of water-curing on the CS of the alkali activated concrete specimens was also investigated. For this purpose, some of the specimens were cured under water for 28 days and shown as $28 \mathrm{~W}$. In addition, the effects of oven-curing (first oven-curing applied) and delayed oven-curing (later oven-curing applied) conditions on the water-cured AACs were also studied. Therefore, some of the specimens cured under water up to $26 \mathrm{~d}$, later oven curing performed at $70^{\circ} \mathrm{C}$ for $48 \mathrm{~h}$ were shown as $26 \mathrm{~W} 2 \mathrm{O}$ to see the effect of delayed oven-curing. Also, some of the specimens were cured in an oven at $70^{\circ} \mathrm{C}$ for $48 \mathrm{~h}$ and then cured under water for 26 days and indicated as $2026 \mathrm{~W}$ to influence of oven-curing (OC) on the CS development of water-cured AACs at 28 days.

The effect of curing duration was also examined on the CS development of the slag and fly ash including AAC specimens. For this purpose, the curing durations of the different curing regimes were further extended up to the 90 days to observe the effect of possible ongoing geopolymeric reactions on the CS development of the AACs. For this aim, 88A2O, 2O88A, 90A curing conditions were examined to influence of OC and DOC on the CS development of the ambient temperature cured AACs. In addition,
$88 \mathrm{~W} 2 \mathrm{O}, 2 \mathrm{O} 88 \mathrm{~W}$, and $90 \mathrm{~W}$ curing conditions were also examined to see the influence of $\mathrm{OC}$ and DOC on CS of the water-cured AAC specimens.

\subsection{Compressive strength}

The CS tests were executed on cube $(150 \times 150 \times 150 \mathrm{~mm})$ samples according to BS EN 12390-3 standard [29]. The AAC specimens were left to dry for $6 \mathrm{~h}$ before the execution of the CS tests for specimens cured in water or in an oven to obtain saturated surface dry condition of the specimens. For each AAC types, 3 companion samples were used to achieve average CS of the specimens. The specimens were loaded under force-controlled with a loading rate of $13.5 \mathrm{kN} / \mathrm{s}$. Most of the studies showed that the mechanical strengths (splitting tensile strength, flexural strength) were directly proportional to CS for AAC $[2,9]$. In addition, previous study showed that the existing formula given by ACI 363-R92 and CEP-FIB for the determination of splitting tensile strength of the specimens using $\mathrm{CS}$ of the specimens were found to be also applicable for the AACs for the $50 \mathrm{MPa}$ compressive strength values [9]. Therefore, the determination of the CS using different curing regimes is significant for the utilization and standardization process of AAC.

\section{Results and discussion}

\subsection{S100 specimens under various curing conditions}

Fig. 1 illustrates the CS test results of the S100 specimens under different curing conditions at the ages of 2 for only OC condition and 28 days for different curing conditions. In Fig. 1, the average values for each values indicated the $\mathrm{CS}$, and top values represented the percentage (\%) ratio of the curing conditions compared to 28A (100\%) curing conditions. The results showed that the CS of the S100 specimen was found to be $15 \mathrm{MPa}$ after oven-curing application

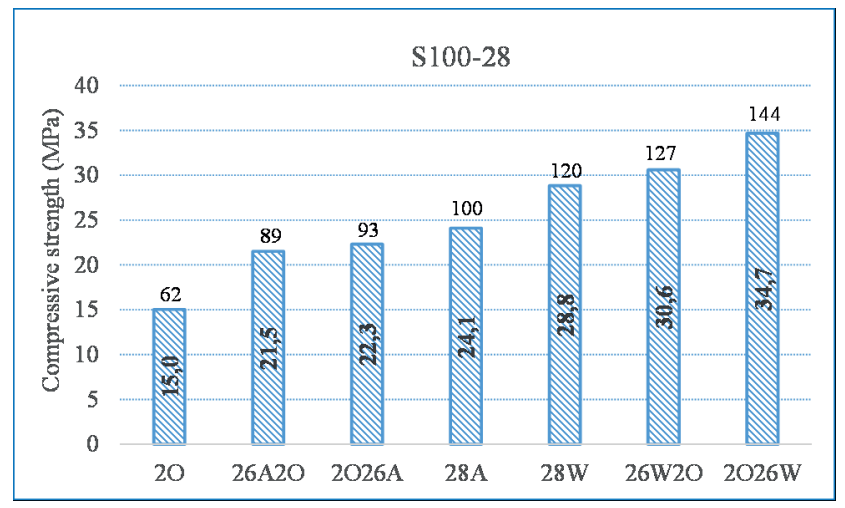

Fig. 1 Compressive strengths of the S100 specimens at 28 days 
at 2 days, which was the $62 \%$ of the CS of $28 \mathrm{~A}$ condition. The minimum and maximum $\mathrm{CS}$ at 28 days were of 21.5 MPa and 34.7 MPa for $26 \mathrm{~A} 2 \mathrm{O}$ and $2 \mathrm{O} 26 \mathrm{~W}$ conditions, respectively. The water-cured specimens exhibited higher CS than the ambient temperature cured specimens at 28 days. The improvements in the CS of the S100 specimens for the $28 \mathrm{~W}, 26 \mathrm{~W} 2 \mathrm{O}$, and $2 \mathrm{O} 26 \mathrm{~W}$ conditions were $20 \%, 27 \%$, and $44 \%$, whilst the reductions for the $26 \mathrm{~A} 2 \mathrm{O}$ and 2O26A conditions were $7 \%$ and $11 \%$ compared to 28A condition, respectively. The result pointed out that oven-curing and delayed oven-curing conditions slightly reduced the CS of the ambient-cured specimens; however, OC and DOC conditions significantly enhanced the CS of the water-cured specimens at 28 days. It is suggested for the $\mathrm{S} 100$ specimens that the best case was found on the $2 \mathrm{O} 26 \mathrm{~W}$ condition ( 2 days oven-curing at $70^{\circ} \mathrm{C}$ for $48 \mathrm{~h}+26$ days under water), whilst the worst case was found on the $26 \mathrm{~A} 2 \mathrm{O}$ condition (26 days under laboratory +2 days oven-curing at $70^{\circ} \mathrm{C}$ for $48 \mathrm{~h}$ ) at 28 days. The CS difference was found to be $13.2 \mathrm{MPa}$ between the $26 \mathrm{~A} 2 \mathrm{O}$ and $2 \mathrm{O} 26 \mathrm{~W}$ conditions for 28 days. The second highest CS was obtained in the delayed oven-curing and water-cured specimens (26W2O) at 28 days, representing the influencing parameter of delayed oven-curing on the CS.

Fig. 2 illustrates the CS results of the S100 specimens at 90 days and the top values give the variation ratio (\%) of different curing conditions compared to 28A condition. The minimum and maximum CS at 90 days were of 25.3 $\mathrm{MPa}$ and $37.4 \mathrm{MPa}$ for $88 \mathrm{~A} 2 \mathrm{O}$ and $90 \mathrm{~W}$ conditions, respectively. The enhancement in the CS of the $\mathrm{S} 100$ specimens was $5 \%$ for $88 \mathrm{~A} 2 \mathrm{O}, 30 \%$ for $2 \mathrm{O} 88 \mathrm{~A}, 49 \%$ for $90 \mathrm{~A}, 44 \%$ for $88 \mathrm{~W} 2 \mathrm{O}, 52 \%$ for $2 \mathrm{O} 88 \mathrm{~W}$, and $55 \%$ for $90 \mathrm{~W}$ conditions compared to 28A condition, respectively. When 90 days of curing period was evaluated, the result pointed out that $\mathrm{OC}$ and DOC conditions significantly reduced the CS of the ambient-cured specimens at 90 days (90A); whilst, OC and DOC conditions slightly decreased the CS of the watercured specimens at 90 days $(90 \mathrm{~W})$. It should be suggested for the S100 specimens that the best case was found the $90 \mathrm{~W}$ condition (90 days under water), whilst the worst case was found $88 \mathrm{~A} 2 \mathrm{O}$ condition ( 88 days under laboratory +2 days oven-curing at $70^{\circ} \mathrm{C}$ for $48 \mathrm{~h}$ ) at the age of 90 days. The results pointed out that delayed oven-curing had a detrimental effect on the CS of the ambient cured S100 specimens at 28 and 90 days. For the water cured specimens, the influence of DOC had a favorable effect on the 28 days, while slight adverse effect compared to the 90 days of CS of S100 AAC specimens.

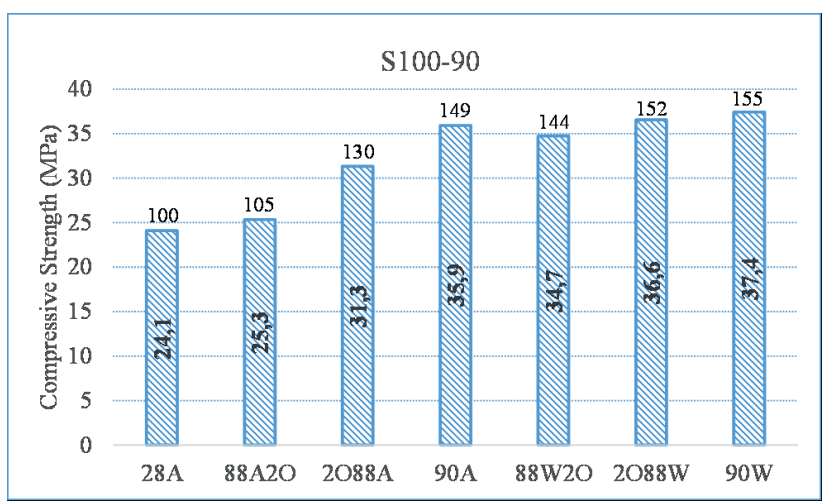

Fig. 2 Compressive strengths of the S100 specimens at 90 days

The CS differences were 11.8 MPa between 28A and $90 \mathrm{~A}, 3.8 \mathrm{MPa}$ between $26 \mathrm{~A} 2 \mathrm{O}$ and $88 \mathrm{~A} 2 \mathrm{O}, 9 \mathrm{MPa}$ between 2026A and 2088A, 2.7 MPa between 28W and $90 \mathrm{~W}, 4.1 \mathrm{MPa}$ between $26 \mathrm{~W} 2 \mathrm{O}$ and $88 \mathrm{~W} 2 \mathrm{O}$, and $1.9 \mathrm{MPa}$ between $2 \mathrm{O} 26 \mathrm{~W}$ and $2 \mathrm{O} 88 \mathrm{~W}$ conditions. The highest and the lowest CS enhancements were obtained in the 90A and 2088W conditions, respectively. The results indicated that ongoing alkali activation reactions occurred in the specimens with time in the S100 specimens.

The CS differences were 4.7 MPa between 28A and $28 \mathrm{~W}, 9.1 \mathrm{MPa}$ between $26 \mathrm{~A} 2 \mathrm{O}$ and $26 \mathrm{~W} 2 \mathrm{O}$, and $12.4 \mathrm{MPa}$ between 2026A and 2026W, whilst $1.5 \mathrm{MPa}$ between $90 \mathrm{~A}$ and $90 \mathrm{~W}, 9.4 \mathrm{MPa}$ between $88 \mathrm{~A} 2 \mathrm{O}$ and $88 \mathrm{~W} 2 \mathrm{O}$, and 5.3 MPa between 2088 A and 2088W conditions, respectively. The results indicated that the CS difference between water and ambient cured specimens became lower with time, except for DOC specimens. Therefore, the effect of water-curing on the CS of S100 specimens was found insignificant, especially for the later ages ( $>90$ days). The similar result was also achieved in the previous research that the CS development was completed after 56 days and no further CS increase was achieved in the slag based AACs [22]. Based on this study, water-curing may not be necessary for the S100 specimens in the long term; however, water-curing enhanced the short term CS of the slag based AACs.

The oven-curing caused CS loss for the ambient cured S100 AAC specimens. Similar results were also obtained in the earlier investigations that poor CS was attributed to the inhomogeneous distributions of geopolymeric reaction products due to the oven-curing, resulting in porous microstructure in the matrix [25]. In addition, the delayed oven-curing affected CS of S100 specimens more adversely than oven-curing conditions. This may be also attributed to the inhomogeneous alkali activation reaction products due to delayed oven-curing, since oven-curing at $70^{\circ} \mathrm{C}$ for $48 \mathrm{~h}$ may cause internal microcracks in the 
hardened matrix, resulting in reduced CS performance. The influence of oven-curing on the water cured S100 specimens was found complicated. The favorable effect of oven-curing was clearly observed in the earlier ages (for 28 days); however, slightly adverse effect of oven-curing was observed for the later ages (for 90 days).

\subsection{S75FA25 specimens under various curing regimes}

Fig. 3 illustrates the CS of the S75FA25 (75\% slag and $25 \%$ fly ash) AACs under different curing conditions at the ages of 2 for only oven-curing condition and 28 days for different curing conditions. The CS of the S75FA25 specimen was found to be $7.2 \mathrm{MPa}$ after oven-curing application at 2 days, which was the $54 \%$ of the CS of $28 \mathrm{~A}$ condition. The lowest and highest CS at 28 days were of $12.6 \mathrm{MPa}$ and $16.3 \mathrm{MPa}$ for $26 \mathrm{~A} 2 \mathrm{O}$ and $26 \mathrm{~W} 2 \mathrm{O}$ conditions, respectively. Similar to S100 specimens, the water-cured specimens exhibited higher CS than the ambient temperature cured specimens at 28 days. The CS enhancements of the S75FA25 specimens for the $28 \mathrm{~W}, 26 \mathrm{~W} 2 \mathrm{O}$, and $2 \mathrm{O} 26 \mathrm{~W}$ conditions were $14 \%, 22 \%$, and $19 \%$ compared to $28 \mathrm{~A}$ condition. However, $5 \%$ reduction for $26 \mathrm{~A} 2 \mathrm{O}$ and $7 \%$ improvement for $2 \mathrm{O} 26 \mathrm{~A}$ conditions were observed compared to $28 \mathrm{~A}$ condition, respectively. The result revealed that DOC condition slightly reduced and OC condition slightly improved the CS of the ambient-cured samples; however, OC and DOC conditions enhanced the CS of the water-cured samples at 28 days. It is suggested for the S75FA25 specimens that the best case was found as delayed oven-curing condition (26W2O-26 days under water and 2 days oven-curing at $70^{\circ} \mathrm{C}$ for $48 \mathrm{~h}$ ), whilst the worst case was found $26 \mathrm{~A} 2 \mathrm{O}$ condition (26 days under laboratory +2 days $\mathrm{OC}$ at $70^{\circ} \mathrm{C}$ for $48 \mathrm{~h}$ ) at 28 days. The CS difference was found to be $27 \%$ between the $26 \mathrm{~A} 2 \mathrm{O}$ and $26 \mathrm{~W} 2 \mathrm{O}$ conditions for 28 days. For the S75FA25 specimens, the delayed oven-curing with water cured specimens showed maximum CS, representing the efficiency of DOC on the CS performance at 28 days.

Fig. 4 illustrates the CS results of the S75FA25 specimens at the age of 90 days. The minimum and maximum $\mathrm{CS}$ at 90 days were of $15 \mathrm{MPa}$ and $21.3 \mathrm{MPa}$ for $88 \mathrm{~A} 2 \mathrm{O}$ and $90 \mathrm{~W}$ conditions, respectively. The enhancement in the CS of the S75FA25 specimens was $13 \%$ for $88 \mathrm{~A} 2 \mathrm{O}, 26 \%$ for $2 \mathrm{O} 88 \mathrm{~A}, 19 \%$ for $90 \mathrm{~A}, 52 \%$ for $88 \mathrm{~W} 2 \mathrm{O}, 55 \%$ for $2 \mathrm{O} 88 \mathrm{~W}$, and $60 \%$ for $90 \mathrm{~W}$ conditions compared to $28 \mathrm{~A}$ condition, respectively. When 90 days of curing period was examined, the oven-curing (2O88A) slightly improved, while the delayed oven-curing (88A2O) slightly reduced the $\mathrm{CS}$ of the specimens compared to ambient-cured specimens at 90 days (90A). Meanwhile, $2 \mathrm{O} 88 \mathrm{~W}$ and $88 \mathrm{~W} 2 \mathrm{O}$ conditions slightly reduced the CS of the water cured specimens compared to 90 days ( $90 \mathrm{~W})$. It is suggested for the S75FA25 specimens that the best case was found the $90 \mathrm{~W}$ condition (90 days under water), whilst the worst case was found $88 \mathrm{~A} 2 \mathrm{O}$ condition ( 88 days under laboratory +2 days oven-curing at $70^{\circ} \mathrm{C}$ for $48 \mathrm{~h}$ ) at the age of 90 days. The results pointed out that DOC had a slight adverse effect on the CS of the ambient cured S75FA25 specimens at the ages of 28 and 90 days. For the water cured specimens, the influence of DOC had a favorable effect on the 28 days, while slight adverse effect compared to 90 days of CS of S75FA25 specimens. For the 90 days, DOC showed almost similar CS with the $90 \mathrm{~W}$ condition, proving that DOC is a significant parameter for the CS development.

The CS differences were 1.9 MPa between 28A and $28 \mathrm{~W}, 3.7 \mathrm{MPa}$ between $26 \mathrm{~A} 2 \mathrm{O}$ and $26 \mathrm{~W} 2 \mathrm{O}$, and $1.5 \mathrm{MPa}$ between 2026A and 2026W, whilst 5.5 MPa between $90 \mathrm{~A}$ and $90 \mathrm{~W}, 5.2 \mathrm{MPa}$ between $88 \mathrm{~A} 2 \mathrm{O}$ and $88 \mathrm{~W} 2 \mathrm{O}$, and 3.8 MPa between 2088A and 2088W conditions, respectively. The results indicated that the CS difference between water and ambient cured specimens increased with the curing time. Differently from S100 specimens, the effect of water-curing on S75FA25 specimens was found significant, especially for the later ages ( $>90$ days).

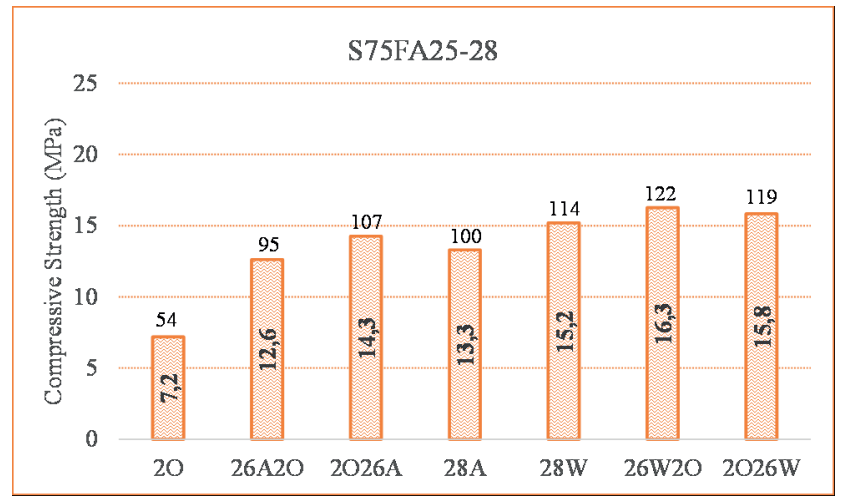

Fig. 3 Compressive strengths of the S75FA25 specimens at 28 days

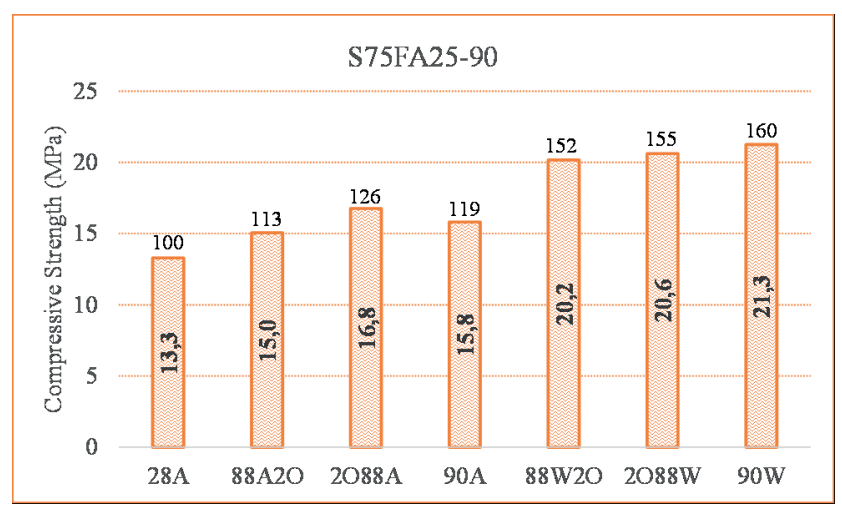

Fig. 4 Compressive strengths of the S75FA25 specimens at 90 days 
The influence of OC on the ambient cured S75FA25 specimens was found complicated. The effect of OC on the early ages (first oven-curing applied) had a favorable effect on the CS for 28 and 90 days, while the DOC application caused the CS loss at 28 and 90 days in the ambient curing conditions. The lower CS of $26 \mathrm{~A} 2 \mathrm{O}$ and $88 \mathrm{~A} 2 \mathrm{O}$ conditions may be attributed to the inhomogeneous alkali activation reaction products due to $\mathrm{DOC}$ and $\mathrm{OC}$ at $70^{\circ} \mathrm{C}$ for $48 \mathrm{~h}$ may cause internal microcracks in the matrix, causing a deterioration in $\mathrm{CS}$.

The influence of OC on the water cured S75FA25 specimens was found complicated. The favorable effect of OC and DOC was observed in the earlier ages (for 28 days); however, slightly adverse effect was noticed for the later ages (for 90 days).

\subsection{S50FA50 specimens under various curing regimes}

Fig. 5 indicates the CS results of the S50FA50 specimens under different curing conditions at the ages of 2 for only oven-curing condition and 28 days for different curing conditions. The CS of the S75FA25 specimen was found to be $3.4 \mathrm{MPa}$ after OC application at 2 days, which was the $144 \%$ of the CS of $28 \mathrm{~A}$ condition. The minimum and maximum CS at 28 days were of $2.4 \mathrm{MPa}$ and $8.6 \mathrm{MPa}$ for $28 \mathrm{~A}$ and 26W2O conditions, respectively. Differently from S100 and S75FA25 specimens, similar CS values were obtained for the water-cured and ambient temperature cured specimens at 28 days. The CS enhancements of the S50FA50 specimens for the $26 \mathrm{~W} 2 \mathrm{O}$ and $2 \mathrm{O} 26 \mathrm{~W}$ conditions were $258 \%$ and $113 \%$ compared to $28 \mathrm{~A}$ condition. Meanwhile, $196 \%$ increase for $26 \mathrm{~A} 2 \mathrm{O}$ and $77 \%$ improvement for 2O26A conditions were observed compared to 28A condition, respectively. The result revealed that DOC and OC significantly enhanced the CS of the both ambient-cured and water cured specimens but tremendous effect of DOC

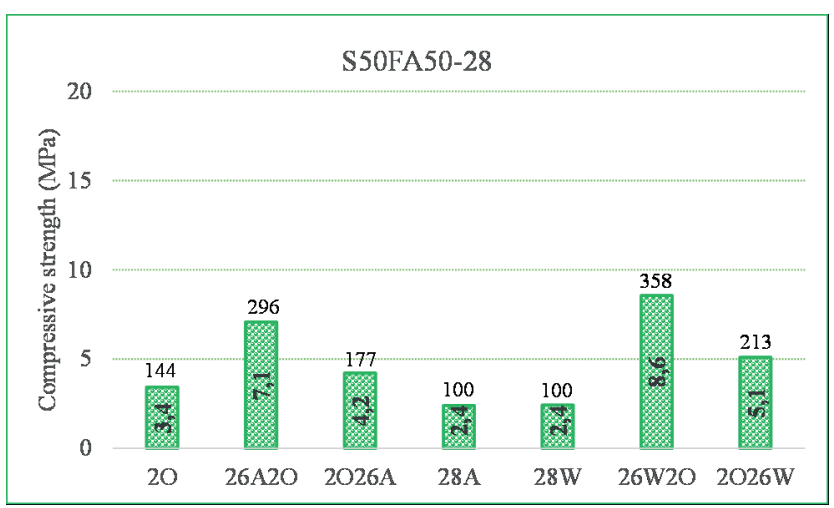

Fig. 5 Compressive strengths of the S50FA50 specimens at 28 days on the water and ambient cured specimens was observed. It is suggested for the S50FA50 specimens that the best case was found as DOC condition (26W2O-26 days under water and 2 days oven-curing at $70^{\circ} \mathrm{C}$ for $48 \mathrm{~h}$ ), whilst the worst case was found in the both $28 \mathrm{~A}$ and $28 \mathrm{~W}$ conditions at 28 days. The DOC with oven-cured specimens showed the highest $\mathrm{CS}$ at 28 days, proving that DOC can be a significant parameter for the early strengths of the AAC.

Fig. 6 illustrates the CS results of the S50FA50 specimens at the age of 90 days. The minimum and maximum CS at 90 days were of 5.3 $\mathrm{MPa}$ and $16.7 \mathrm{MPa}$ for 2088A and 90W conditions, respectively. The enhancement in the CS of the S50FA50 specimens was $198 \%$ for $88 \mathrm{~A} 2 \mathrm{O}, 120 \%$ for $2 \mathrm{O} 88 \mathrm{~A}, 390 \%$ for $90 \mathrm{~A}, 277 \%$ for $88 \mathrm{~W} 2 \mathrm{O}, 169 \%$ for $2 \mathrm{O} 88 \mathrm{~W}$, and $598 \%$ for $90 \mathrm{~W}$ conditions compared to $28 \mathrm{~A}$ condition, respectively. When 90 days of curing period was examined, the OC and DOC significantly reduced the CS of the ambient cured and water cured specimens. It is suggested for the S50FA50 AAC specimens that the best case was found at the $90 \mathrm{~W}$ condition (90 days under water), whilst the worst case was found at the $2 \mathrm{O} 88 \mathrm{~A}$ condition ( 2 days oven-curing at $70^{\circ} \mathrm{C}$ for $48 \mathrm{~h}+88$ days under laboratory) at 90 days.

The CS differences were 1.5 MPa between 26A2O and 26W2O, and 0.9 MPa between 2O26A and 2O26W, whilst $5 \mathrm{MPa}$ between 90A and 90W, 1.9 MPa between 88A2O and $88 \mathrm{~W} 2 \mathrm{O}$, and $1.1 \mathrm{MPa}$ between 2088A and 2088W conditions, respectively. The results indicated that similar CS difference between water and ambient cured specimens were obtained. Differently from S100 specimens, the effect of water-curing on S50FA50 specimens was found significant, especially for the later ages ( $>90$ days).

The influence of OC on the ambient cured S50FA50 specimens was found complicated. The effect of $\mathrm{OC}$ and DOC on the early ages had favorable effects on the CS

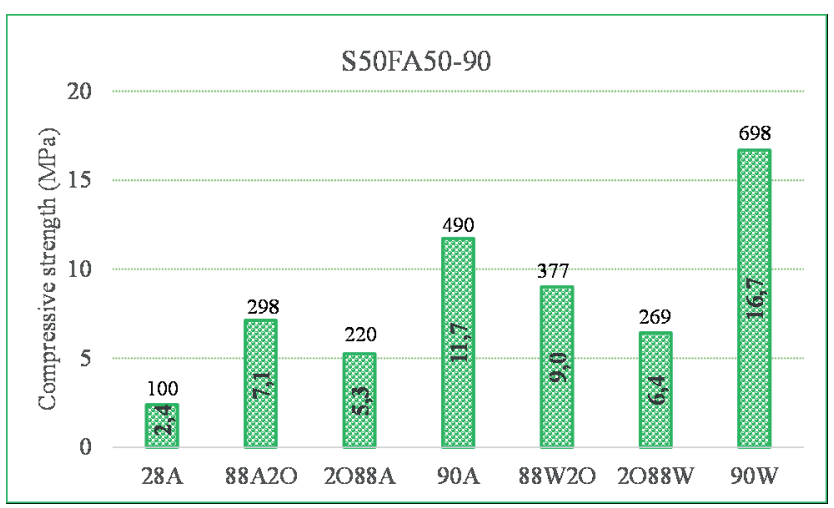

Fig. 6 Compressive strengths of the S50FA50 specimens at 90 days 
for 28 days, whilst reduced the CS results at later ages. The influence of OC on the water cured S50FA50 specimens was found similar with the ambient cured specimens. The favorable effect of OC and DOC was observed in the earlier ages (for 28 days); however, slightly adverse effect was noticed for the later ages (for 90 days).

The results indicated that CS of the OC and DOC specimens increased with time despite the initial heat curing at $70^{\circ} \mathrm{C}$ at $48 \mathrm{~h}$. In an earlier investigation, it was stated that the CS increase was stabilized after 56 days later for the slag based AAC specimens even without oven-curing, while CS increase continued up to 540 days despite initial $\mathrm{OC}$ of $80^{\circ} \mathrm{C}$ at $24 \mathrm{~h}$ for the GPC specimens [22]. The similar results also obtained in the study.

The reason of the poor CS of the OC fly ash including AAC specimens can be attributed to; i) lower activity of fly ash particles [30], ii) alkali activator type and amount [31], iii) low $\mathrm{CaO}$ content in fly ash particles [32]. In addition, previous studies showed that alkali activator amount was an important parameter and the decrease of the CS can be expected when sodium silicate to sodium hydroxide ratio becomes higher than 2 . For the smaller ratios, the improved $\mathrm{CS}$ may be attributed to the increasing $\mathrm{Na}$ content since $\mathrm{Na}$ ions take place at the geopolymerization process as a charge balancing ion. For the higher sodium silicate to sodium hydroxide ratio of 2 , the escape of water and the $3 \mathrm{D}$ aluminosilicate geopolymer network formation are hindered, which prevent the geopolymerization, causing a reduction in the CS due to the high insoluble sodium silicate content $[33,34]$. In this study, sodium silicate to sodium hydroxide ratio was utilized as 2.5 , which may be one of the factors of the obtained poor CS for the fly ash based AACs. Meanwhile, the microstructure of the slag based AACs was denser due to the improved C-S-H gel formation [35].

The difference between the mixes was the F-type fly ash addition. Due to the low $\mathrm{CaO}$ content and slow geopolymeric reactions, fly ash incorporating mixes performed lower CS values. The reduction in the CS values was found to be more with higher fly ash incorporations. Therefore, S50FA50 specimens yielded the lowest CS, while S100 specimens performed superior CS.

\section{Conclusions}

In this research, the influence of different curing conditions on the compressive strength (CS) of AAC specimens was investigated at 2, 28, and 90 days. The oven-curing
(OC) at $70^{\circ} \mathrm{C}$ for $48 \mathrm{~h}$, water-curing, and ambient temperature $(\mathrm{AC})$ curing conditions were studied with various configurations on the $100 \%$ ground granulated blast furnace slag based (S100), $75 \%$ ground granulated blast furnace slag based $+25 \%$ fly ash based (S75FA25), and $50 \%$ ground granulated blast furnace slag based $+50 \%$ fly ash based (S50FA50) AAC specimens. In addition, the influence delayed oven curing (DOC) condition on the $\mathrm{CS}$ results was evaluated. The following outcomes for the AAC specimens were obtained:

- The results indicated that CS of the all specimens increased with curing time with a decreasing rate.

- The specimens cured under water + oven-curing conditions yielded higher CS than the ambient temperature + oven-curing conditions.

- The water curing was found as the best condition for the superior CS of the all specimens at 90d.

- For S100 specimens, best cases for the CS were 2O26W condition for $28 \mathrm{~d}$ and $90 \mathrm{~W}$ conditions for $90 \mathrm{~d}$, whilst worst cases were $26 \mathrm{~A} 2 \mathrm{O}$ condition for $28 \mathrm{~d}$ and $88 \mathrm{~A} 2 \mathrm{O}$ condition for $90 \mathrm{~d}$.

- For S75FA25 specimens, best cases for the CS were $26 \mathrm{~W} 2 \mathrm{O}$ condition for $28 \mathrm{~d}$ and $90 \mathrm{~W}$ condition for $90 \mathrm{~d}$, whilst worst cases were $26 \mathrm{~A} 2 \mathrm{O}$ condition for $28 \mathrm{~d}$ and $88 \mathrm{~A} 2 \mathrm{O}$ condition for $90 \mathrm{~d}$.

- For S50FA50 specimens, best cases for CS were $26 \mathrm{~W} 2 \mathrm{O}$ condition for $28 \mathrm{~d}$ and $90 \mathrm{~W}$ condition for $90 \mathrm{~d}$, whilst worst cases were both $28 \mathrm{~A}$ and $28 \mathrm{~W}$ conditions for $28 \mathrm{~d}$ and $2088 \mathrm{~A}$ condition for $90 \mathrm{~d}$.

- The delayed oven curing condition (DOC) was obtained an important parameter for the CS at $28 \mathrm{~d}$. The CS of DOC at $90 \mathrm{~d}$ was also found better than the most of the curing conditions.

- The OC and DOC conditions enhanced the CS of water-cured specimens for S100, S75FA25, and S50FA50 specimens, whilst no obvious effect was found on the ambient-cured specimens at $28 \mathrm{~d}$.

- The OC and DOC conditions reduced the CS, except for the slight increase in the CS for the OC condition of the ambient cured S75FA25 specimens at 90d.

- The effect of water-curing on CS of the S100 specimens was found insignificant, whilst it significantly improved CS of the both S75FA25 and S50FA50 specimens, especially at later ages.

- S100 specimens can be utilized in structural applications without oven-curing and water-curing. 


\section{References}

[1] Soutsos, M., Boyle, A. P., Vinai, R., Hadjierakleous, A., Barnett, S. J. "Factors influencing the compressive strength of fly ash based geopolymers", Construction and Building Materials, 110, pp. 355$368,2016$.

https://doi.org/10.1016/j.conbuildmat.2015.11.045

[2] Kurtoglu, A. E., Alzeebaree, R., Aljumaili, O., Nis, A., Gulsan, M. E., Humur, G., Cevik, A. "Mechanical and durability properties of fly ash and slag based geopolymer concrete", Advances in Concrete Construction, 6(4), pp. 345-362, 2018.

https://doi.org/10.12989/acc.2018.6.4.345

[3] Provis, J. L. "Geopolymers and other alkali activated materials: why, how, and what?", Materials and Structures, 47, pp. 11-25, 2014. https://doi.org/10.1617/s11527-013-0211-5

[4] Huseien, G. F., Sam, A. R. M., Shah, K. W., Mirza, J. "Effects of ceramic tile powder waste on properties of self-compacted alkali-activated concrete", Construction and Building Materials, 236, Article No. 117574, 2020.

https://doi.org/10.1016/j.conbuildmat.2019.117574

[5] Aragón, P., Robayo-Salazar, R. A., Mejía de Gutiérrez, R. "AlkaliActivated Concrete Based on Natural Volcanic Pozzolan: Chemical Resistance to Sulfate Attack", Journal of Materials in Civil Engineering, 32(5), Article No. 04020106, 2020. https://doi.org/10.1061/(ASCE)MT.1943-5533.0003161

[6] Ikponmwosa, E. E., Ehikhuenmen, S., Emeshie, J., Adesina, A. "Performance of Coconut Shell Alkali-Activated Concrete: Experimental Investigation and Statistical Modelling", Silicon, 2020. https://doi.org/10.1007/s12633-020-00435-z

[7] Yuan, B., Yuan, S., Straub, C., Chen, W. "Activation of Binary Binder Containing Fly Ash and Portland Cement Using Red Mud as Alkali Source and Its Application in Controlled Low-Strength Materials", Journal of Materials in Civil Engineering, 32(2), Article No. 04019356, 2020.

https://doi.org/10.1061/(ASCE)MT.1943-5533.0003023

[8] Alzeebaree, R., Çevik, A., Mohammedameen, A., Niş, A., Gülşan, M. E. "Mechanical performance of FRP-confined geopolymer concrete under seawater attack", Advances in Structural Engineering, 23(6), pp. 1055-1073, 2019.

https://doi.org/10.1177/1369433219886964

[9] Çevik, A., Alzeebaree, R., Humur, G., Niş, A., Gülşan, M. E. "Effect of nano-silica on the chemical durability and mechanical performance of fly ash based geopolymer concrete", Ceramics International, 44(11), pp. 12253-12264, 2018. https://doi.org/10.1016/j.ceramint.2018.04.009

[10] Niş, A., Altundal, M. B. "Mechanical strength degradation of slag and fly ash based geopolymer specimens exposed to sulfuric acid attack", [pdf] Sigma Journal of Engineering and Natural Sciences, 37(3), pp. 917-926, 2019. Available at: file://C:/Users/ user/Downloads/YTUJENS-2019-37-3.5036.pdf

[11] Ma, Y., Ye, G. "The shrinkage of alkali activated fly ash", Cement and Concrete Research, 68, pp. 75-82, 2015. https://doi.org/10.1016/j.cemconres.2014.10.024

[12] Giosuè, C., Mobili, A., Di Perna, C., Tittarelli, F. "Performance of lightweight cement-based and alkali-activated mortars exposed to high-temperature", Construction and Building Materials, 220, pp. 565-576, 2019. https://doi.org/10.1016/j.conbuildmat.2019.05.193
[13] Jang, J. G., Lee, N. K., Lee, H. K. "Fresh and hardened properties of alkali-activated fly ash/slag pastes with superplasticizers", Construction and Building Materials, 50, pp. 169-176, 2014. https://doi.org/10.1016/j.conbuildmat.2013.09.048

[14] Bakharev, T. "Geopolymeric materials prepared using Class F fly ash and elevated temperature curing", Cement and Concrete Research, 35(6), pp. 1224-1232, 2005.

https://doi.org/10.1016/j.cemconres.2004.06.031

[15] Ma, C.-K., Awang, A. Z., Omar, W. "Structural and material performance of geopolymer concrete: A review", Construction and Building Materials, 186, pp. 90-102, 2018. https://doi.org/10.1016/j.conbuildmat.2018.07.111

[16] Chi, M. "Effects of dosage of alkali-activated solution and curing conditions on the properties and durability of alkali-activated slag concrete", Construction and Building Materials, 35, pp. 240-245, 2012.

https://doi.org/10.1016/j.conbuildmat.2012.04.005

[17] Helmy, A. I. I. "Intermittent curing of fly ash geopolymer mortar", Construction and Building Materials, 110, pp. 54-64, 2016. https://doi.org/10.1016/j.conbuildmat.2016.02.007

[18] Palomo, A., Grutzeck, M. W., Blanco, M. T. "Alkali-activated fly ashes A cement for the future", Cement and Concrete Research, 29, pp. 1323-1329, 1999. https://doi.org/10.1016/S0008-8846(98)00243-9

[19] Ma, Y., Hu, J., Ye, G. "The pore structure and permeability of alkali activated fly ash", Fuel, 104, pp. 771-780, 2013. https://doi.org/10.1016/j.fuel.2012.05.034

[20] van Jaarsveld, J. G. S., van Deventer, J. S. J., Lukey, G. C. "The effect of composition and temperature on the properties of fly ashand kaolinite-based geopolymers", Chemical Engineering Journal, 89(1-3), pp. 63-73, 2002. https://doi.org/10.1016/S1385-8947(02)00025-6

[21] Li, X., Wang, Z., Jiao, Z. "Influence of Curing on the Strength Development of Calcium-Containing Geopolymer Mortar", Materials, 6(11), pp. 5069-5076, 2013. https://doi.org/10.3390/ma6115069

[22] Wardhono, A., Gunasekara, C., Law, D. W., Setunge, S. "Comparison of long term performance between alkali activated slag and fly ash geopolymer concretes", Construction and Building Materials, 143, pp. 272-279, 2017. https://doi.org/10.1016/j.conbuildmat.2017.03.153

[23] Aliabdo, A. A., Abd Elmoaty, A. E. M., Emam, M. A. "Factors affecting the mechanical properties of alkali activated ground granulated blast furnace slag concrete", Construction and Building Materials, 197, pp. 339-355, 2019. https://doi.org/10.1016/j.conbuildmat.2018.11.086

[24] Hardjito, D., Wallah, S. E., Sumajouw, D. M. J., Rangan, B. V. "On the Development of Fly Ash-Based Geopolymer Concrete", ACI Materials Journal, 101(6), pp. 467-472, 2004.

[25] El-Hassan, H., Shehab, E., Al-Sallamin, A. "Influence of Different Curing Regimes on the Performance and Microstructure of Alkali-Activated Slag Concrete", Journal of Materials in Civil Engineering, 30(9), Article No. 04018230, 2018. https://doi.org/10.1061/(ASCE)MT.1943-5533.0002436 
[26] Izquierdo, M., Querol, X., Phillipart, C., Antenucci, D., Towler, M. "The role of open and closed curing conditions on the leaching properties of fly ash-slag-based geopolymers", Journal of Hazardous Materials, 176, pp. 623-628, 2010. https://doi.org/10.1016/j.jhazmat.2009.11.075

[27] Lee, S., Van Riessen, A., Chon, C.-M. "Benefits of Sealed-Curing on Compressive Strength of Fly Ash-Based Geopolymers", Materials, 9(7), Article No. 598, 2016. https://doi.org/10.3390/ma9070598

[28] Kumaravel, S., Girija, K. "Acid and salt resistance of geopoly-

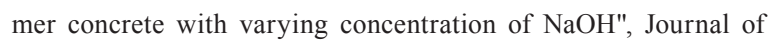
Engineering Research and Studies, 4(4), pp. 1-3, 2013.

[29] BSI "BS EN 12390-3:2019 Testing hardened concrete. Compressive strength of test specimens", British Standards Institution, London, UK, 2019.

[30] Chi, M., Huang, R. "Binding mechanism and properties of alkali-activated fly ash/slag mortars", Construction and Building Materials, 40, pp. 291-298, 2013. https://doi.org/10.1016/j.conbuildmat.2012.11.003

[31] Ridtirud, C., Chindaprasirt, P., Pimraksa, K. "Factors affecting the shrinkage of fly ash geopolymers", International Journal of Minerals, Metallurgy, and Materials, 18(1), pp. 100-104, 2011. https://doi.org/10.1007/s12613-011-0407-z
[32] Dombrowski, K., Buchwald, A., Weil, M. "The influence of calcium content on the structure and thermal performance of fly ash based geopolymers", Journal of Materials Science, 42, pp. 30333043, 2007. https://doi.org/10.1007/s10853-006-0532-7

[33] Reddy, M. S., Dinakar, P., Rao, B. H. "Mix design development of fly ash and ground granulated blast furnace slag based geopolymer concrete", Journal of Building Engineering, 20, pp. 712-722, 2018. https://doi.org/10.1016/j.jobe.2018.09.010

[34] Gao, K., Lin, K.-L., Wang, D., Hwang, C.-L., Shiu, H.-S., Chang, Y.-M., Cheng, T.-W. "Effects $\mathrm{SiO}_{2} / \mathrm{Na}_{2} \mathrm{O}$ molar ratio on mechanical properties and the microstructure of nano- $\mathrm{SiO}_{2}$ metakaolin-based geopolymers", Construction and Building Materials, 53, pp. 503510, 2014.

https://doi.org/10.1016/j.conbuildmat.2013.12.003

[35] Kumar, S., Kumar, R., Mehrotra, S. P. "Influence of granulated blast furnace slag on the reaction, structure and properties of fly ash based geopolymer", Journal of Materials Science, 45, pp. 607-615, 2010. https://doi.org/10.1007/s10853-009-3934-5 